\title{
A EVASÃO ESCOLAR NA ADOLESCÊNCIA SOB O OLHAR DA PSICOLOGIA: REVISÃO DE LITERATURA ${ }^{1}$
}

\author{
SCHOOL DROPOUT IN ADOLESCENCE FROM THE \\ POINT OF VIEW OF PSYCHOLOGY: LITERATURE REVIEW
}

\section{Elisa Cortes Rehbein ${ }^{2}$, Mariana Kirst Pereira ${ }^{3}$, Victória Berwanger ${ }^{4}$, Fernanda Pires Jaeger ${ }^{5}$ e Janaína Pereira Pretto Carlesso ${ }^{6}$}

\section{RESUMO}

O objetivo do presente artigo consistiu em analisar as causas e consequências da evasão escolar na adolescência. Trata-se de uma pesquisa bibliográfica de método qualitativo sob um viés hipotético-dedutivo na qual a coleta de dados foi realizada no período de agosto a outubro de 2020. As fontes bibliográficas utilizadas foram teses, artigos eletrônicos nacionais e livros encontrados nas bases de dados do Google Acadêmico, Pepsic, Scielo e Bireme. A evasão é um fenômeno complexo e gradativo que, apesar de ter reduzido nos últimos anos, envolve questões internas e externas, como aspectos sociais, econômicos, familiares e do próprio sistema escolar, levando em conta a desafiadora fase da adolescência. O papel da ciência psicológica é fundamental para o entendimento desse impasse que deve ser melhor debatido e viabilizado, dado que a educação é um direito de todos por constar na Constituição Federal vigente. Logo, modificando as práticas educacionais e a maneira dos estudantes de dialogarem com os professores e consigo mesmos, auxiliando em uma realidade crítica e transformadora.

Palavras-chave: Adolescência; Escola; Evasão; Psicologia.

\section{ABSTRACT}

The objetive of the present article consisted to analyze the causes and consequences of school dropout in adolescence. This is a bibliographic and qualitative research under the hypothetico-deductive bias which data collection was performed from August to October 2020. The bibliographical sources used were theses, nacional electronic articles and books found in the databases of Google Scholar, Scielo and Bireme. Evasion is a complex and gradual phenomenon that, despite the reduction in recent years, involves internal and external issues, such as social, economic, familiar and school system aspects, considering the challenging phase of adolescence. The role of Psychology is fundamental to understand the impasse that should be more granted and debated, since Education is everybody's right that appears in the current Federal Constitution. Therefore, modifying educacional practices and the way students dialogue with teachers and themselves, assisting in a critical and transformative reality.

Keywords: Adolescence; School; Dropout; Psychology.

1 Artigo integrado das disciplinas de Escrita Científica e Pesquisa em Psicologia I e Psicologia da Adolescência.

2 E-mail: e.rehbein@ufn.edu.br

3 E-mail: kirst.mariana@ufn.edu.br

4 E-mail: victoriaberwangerr@gmail.com

5 E-mail: fernandajaeger19@gmail.com

6 E-mail: janaina.carlesso@ufn.edu.br 


\section{INTRODUÇÃO}

O presente artigo visa apresentar a temática da evasão escolar entre os adolescentes no contexto das suas causas e consequências que os conduzem a este desfecho. $\mathrm{O}$ abandono escolar representa um prejuízo significativo, visto que se refere ao fundamental estágio da vida caracterizado pela enriquecedora fase de desenvolvimento cognitivo, intelectual e subjetivo da adolescência. Além de abster-se dos benefícios que lhe trariam no âmbito social ao conviver com jovens da mesma faixa etária, muito há de se analisar. As oportunidades de uma boa qualidade de vida no futuro em relação ao crescimento pessoal e profissional poderão ser pouco promissoras comparadas ao que deixou de vivenciar ao não exercer seu direito básico da educação. Logo, o questionamento se dá na perspectiva de que a evasão escolar é um grave empecilho dado o papel essencial do ambiente de promover a construção moral e ética. Ainda, quanto à socialização e transmissão de conhecimento teórico, prático e intelectual no intuito de transformar o próprio estudante em um indivíduo crítico de maneira a contribuir com a sociedade.

Diante disso, pondera-se a respeito das mais variadas, recorrentes e por vezes concomitantes circunstâncias atuais que levam jovens de diferentes realidades a se desmotivarem e desistirem da instituição de ensino. Considera-se, então, a possibilidade de a discussão estar relacionada a contextos familiares, em que há problemas de convívio; a aspectos sociais gerais, como em camadas desfavorecidas da sociedade na qual recursos básicos são precários e se faz necessário auxiliar na renda ingressando no trabalho informal; e a influência da escola por não se enquadrar como um local agradável, organizado e adequado, provocando a desistência do aluno.

Sendo o ambiente escolar fundamental à aprendizagem, vida e subjetividade dos indivíduos na contemporaneidade desde a primeira infância, a escolha do tema do presente trabalho se dá pelo interesse em investigar as causas da evasão. Esse, dedica-se a discorrer acerca do que impulsiona os jovens a renunciarem à importante instituição considerada de grande relevância ao crescimento íntegro e pessoal. Sendo pontualmente decisiva no que se refere à formação e efetividade profissional, é crucial analisar suas repercussões visto que na prática há brechas no funcionamento da escola que negligenciam o seu objetivo para com o corpo social. Diante disso, faz-se necessário entender e informar à população quanto aos reflexos dos motivos e implicações da decisão tomada pelos jovens e/ou responsáveis.

Partindo desta explanação, este trabalho foi norteado por uma questão problema: quais são as causas e as consequências da evasão escolar na adolescência? Posto isto, como objetivo, o presente trabalho visa analisar como tais fatores estão associados à evasão escolar na adolescência, examinando o contexto familiar dos adolescentes evadidos, assim como o papel da escola e da psicologia nessa conjuntura. 


\section{METODOLOGIA}

Para a realização desse trabalho foi realizada a pesquisa bibliográfica. Segundo Gil (2008), a pesquisa bibliográfica caracteriza-se por ser desenvolvida a partir de material já publicado. Ela é elaborada a partir de buscas em livros, artigos, periódicos, dissertações e teses e periódicos eletrônicos e sua relevância se configura ao proporcionar dados e informações que servem de subsídio para a elaboração do estudo, caracterizando uma investigação aprofundada.

A abordagem metodológica utilizada foi a pesquisa qualitativa sob um viés hipotético-dedutivo. De acordo com Lincoln e Denzin (2006), a pesquisa qualitativa diz respeito a uma perspectiva interpretativa das situações, sendo que os pesquisadores tentam entender o significado dos fenômenos a partir do que eles representam para os indivíduos. Do mesmo modo, para Minayo (2002), esse tipo de pesquisa se relaciona com as questões mais profundas das relações do indivíduo com si próprio e com os outros e, sendo assim, ela não pode ser reduzida à quantificação de dados e variáveis.

A coleta de dados foi realizada no período de agosto a outubro de 2020. As fontes bibliográficas que foram utilizadas são artigos eletrônicos nacionais referentes aos últimos dez anos, assim como alguns livros. A pesquisa do material foi realizada nas seguintes bases de dados eletrônicas: Google acadêmico, Bireme (Biblioteca virtual em saúde), Pepsic e Scielo. Para realizar a busca desse material, foram utilizadas as seguintes palavras-chave: evasão escolar, adolescentes, adolescência. Os critérios empregados para a seleção do material bibliográfico foram a leitura dos resumos dos artigos relacionados à temática do artigo. Os artigos previamente selecionados a partir desses critérios serão lidos inteiramente para a última seleção.

Para a análise dos dados coletados, foi utilizada a análise de conteúdo proposta por Laurence Bardin (1977) em seu livro “Análise de Conteúdo". Esse livro apresenta os passos que devem ser seguidos para realizar uma análise científica. De acordo com a autora, a primeira etapa é a pré-análise em que se organiza os materiais, de forma metódica, para verificar o que já está disponível. A segunda etapa diz respeito à exploração do material, enumerando-o e categorizando-o de acordo com os critérios estabelecidos. Já a terceira e última etapa consiste no tratamento dos resultados obtidos, assim como a sua posterior interpretação.

\section{RESULTADOS E DISCUSSÕES}

\section{INFLUÊNCIA DOS ASPECTOS SOCIAIS NA EVASÃO ESCOLAR}

De acordo com a Constituição Federal de 1988, a educação é um direito de todos. Esse direito caminha no sentido de uma diminuição das desigualdades sociais. No entanto, apesar de o acesso à educação ser universal, a permanência do aluno no sistema escolar não é. Nesse sentido, 
a continuidade escolar de adolescentes autores de atos infracionais configura-se como um impasse, já que constantemente esses jovens são caracterizados como "bandidos" ou "delinquentes", o que os desmotiva a continuar frequentando o ambiente escolar.

Conforme assegurado no Estatuto da Criança e do Adolescente (ECA), os jovens em cumprimento de medida socioeducativa devem frequentar a escola. Contudo, observa-se que grande parte desses adolescentes estão evadidos da escola quando fora da internação. Uma pesquisa realizada por Priscila Carla Cardoso e Débora Cristina Fonseca analisou cinco entrevistas com adolescentes, todos do sexo masculino, na faixa etária entre 16 e 17 anos, evadidos da escola, e concluiu que todos indicaram dificuldades em relação ao processo de ensino-aprendizagem, assim como sua própria culpabilização pelo fracasso escolar.

Percebe-se, a partir disso, que:

Parece haver uma normatização, por parte da escola, das identidades destes adolescentes, sempre visando à manutenção do lugar dos excluídos, sendo eles paralisados pela reposição de identidades pressupostas. Há uma constante reposição das identidades a eles atribuídas e a incorporação do discurso de culpabilização do indivíduo pelo fracasso escolar, que se concretizou ao longo das suas histórias escolares, sintetizando-se na identidade de "aluno problema" (CARDOSO e FONSECA, 2019, p. 6).

Do mesmo modo, segundo Gallo e Williams (2008), um dos maiores problemas que a escola enfrenta em relação a esses jovens é a dificuldade em lidar com os comportamentos difíceis desses alunos, o que os leva a adotarem medidas disciplinares coercitivas, facilitando a evasão escolar. Infere-se, portanto, que apesar de haver uma diretriz para a inclusão desses adolescentes no ambiente escolar, constantemente eles estão evadindo das escolas por uma inclusão deficitária e não coerente com suas reais necessidades.

No sentido de viabilizar condições iguais de ensino para todos os estudantes, Cardoso e Fonseca (2019, p. 10) apontam que os professores erroneamente ensinam da mesma forma, deixando de levar em consideração a realidade de cada um. Dadas as diferentes condições psíquicas e sociais dos alunos, para que as escolas cumpram seu papel de instigar a curiosidade e transformação, devem ser implantadas práticas distintas de aprendizagem. Além disso, preparar professores para que se engajem com compromisso no sentido de construir conhecimento junto ao aluno de maneira singular e inclusiva, em contrapartida ao sistema maçante, alienante e antiquado que persiste na atualidade brasileira.

A respeito da temática, evidenciam-se aspectos socioculturais e econômicos significativos que impulsionam a evasão e o abandono dos estudos. Fatores significativos se dão na violência e na gravidez na adolescência, esta, destacada em famílias de baixa renda devido ao limitado acesso à educação, refletindo na responsabilidade e disponibilização de tempo em outro âmbito da vida. A violência é representada pelo bullying, bem como pela violência territorial, pois muitas vezes as escolas estão localizadas em locais de intensa exclusão social. 
No que diz respeito ao bullying, "este tipo de violência desperta tanto na vítima quanto no agressor uma desmotivação e falta de interesse em frequentar a escola”. Logo, torna-se notável a dificuldade do acesso e a permanência de brasileiros na escola, sobretudo dos menos favorecidos, que, apesar de terem sido melhor focalizados nos últimos anos, tais impasses retardatários da igualdade e educação para todos perduram na sociedade complicando o acesso ao conhecimento e favorecendo a miséria e a desigualdade social.

Além desses fatores, um considerável propulsor desse grave problema se dá na necessidade dos jovens de trabalhar para contribuir com a renda familiar. Devido à tamanha energia a ser demandada destinada a duas atividades, a escola, que já não é um ambiente atrativo, traduz-se em um rendimento inferior comparado aos que apenas estudam e muitas vezes consequentemente é abandonada. Em se tratando dos aspectos sociais, percebe-se que:

Em todas as dimensões, os indicadores mostram que os grupos mais vulneráveis são aqueles historicamente excluídos da sociedade brasileira: as populações negra e indígena, as pessoas com deficiência, as que vivem nas zonas rurais e as famílias com baixa renda. (SOUZA, 2017, p. 5).

Visto isso, salienta-se que mesmo que o Brasil seja composto por cerca de $56 \%$ da população negra (IBGE - Instituto Brasileiro de Geografia e Estatística, Pesquisa Nacional por Amostra de Domicílios Contínua, 2018) o preconceito e a discriminação racial continuam fomentando a miséria, ao passo que a desigualdade social segue exorbitante apesar da redução nas últimas décadas, as oportunidades educacionais não são as mesmas, sendo grande indicadores da evasão.

Evidencia-se, inclusive, que os profissionais, desinteressados pelo trabalho exaustivo, são também desqualificados para proporcionar a adequada acessibilidade para com alunos com deficiência. A péssima qualidade dos transportes escolares e a infraestrutura precária desfavorecem bastante também estudantes de comunidades rurais, quilombolas e indígenas. Outro fator de desmotivação é a enorme diferença entre a realidade desses alunos e aquela apresentada nos materiais didáticos. Ademais, Silva Filho e Araújo (2017) acentuam que:

Fatores internos e externos, como drogas, tempo na escola, sucessivas reprovações, falta de incentivo da família e da escola, necessidade de trabalhar, excesso de conteúdo escolar, alcoolismo, localização da escola, vandalismo, falta de formação de valores e preparo para o mundo do trabalho, podem ser considerados decisivos no momento de ficar ou sair da escola, engrossando a fila do desemprego. (SILVA FILHO; ARAÚJO, 2017).

Por isso, os diversos e plurais aspectos sociais se mostram decisivos e propulsores do fenômeno do abandono escolar, dado que o sistema escolar é conivente ao processo de segregação social. Esse, ao colaborar com o aumento dos índices de exclusão principalmente dos menos desfavorecidos por não estar habilitado e nem respeitar as diferenças que garanta o direito de uma educação de qualidade que instigue desde cedo a visão crítica, empática e promova um desenvolvimento saudável por meio de métodos de 
aprendizagem diferenciados (dando enfoque à singularidade de cada estudante) e professores realmente interessados que não negligentemente trabalham com conhecimentos acumulados e pragmáticos.

Dessa maneira, segundo Rumberger (2006, apud MENDES, 2013) reconhecer e listar todas as causas da evasão é uma tarefa árdua, já que este fenômeno é determinado por inúmeros fatores, como os citados acima. Portanto, entende-se que a evasão é um processo que vai ocorrendo aos poucos, não surgindo em um momento específico da vida do jovem. Quando esse jovem efetivamente evade da escola, esse é o fim de um processo cumulativo de inúmeros problemas que fizeram o estudante se desinteressar pela escola e/ou ter necessidade de deixar esse ambiente por necessidade.

Não se nasce excluído, não se está sempre excluído. A exclusão tem relação com trajetórias de vida diferentes, nas quais relações étnicas, raciais, de gênero, de classe, entre outras, são importantes. É necessário entender quais são os processos que atravessam a vida das instituições educacionais, e nestas compreender o que provoca situação de exclusão. A Evasão Escolar é uma tarefa importante para a busca de solução na pedagogia, na sociologia da educação, na psicologia da educação e da aprendizagem, etc. analisando como se desfaz os processos educacionais, que garantam uma escolaridade significativa paras as crianças e jovens e reduza substancialmente a Evasão Escolar. (FORMIGA, et al. 2011)

Considerando a significativa relação dos adolescentes evadidos com os aspectos socioeconômicos e suas implicações no cotidiano, evidencia-se, segundo dados da Síntese de Indicadores Sociais do IBGE, de 2019, que os sistemas relacionais atuais representam e refletem a estrutura e organização social vigente

Gráfico 1 - Situação escolar de jovens entre 15 e 17 anos (\%) por faixa de rendimento.

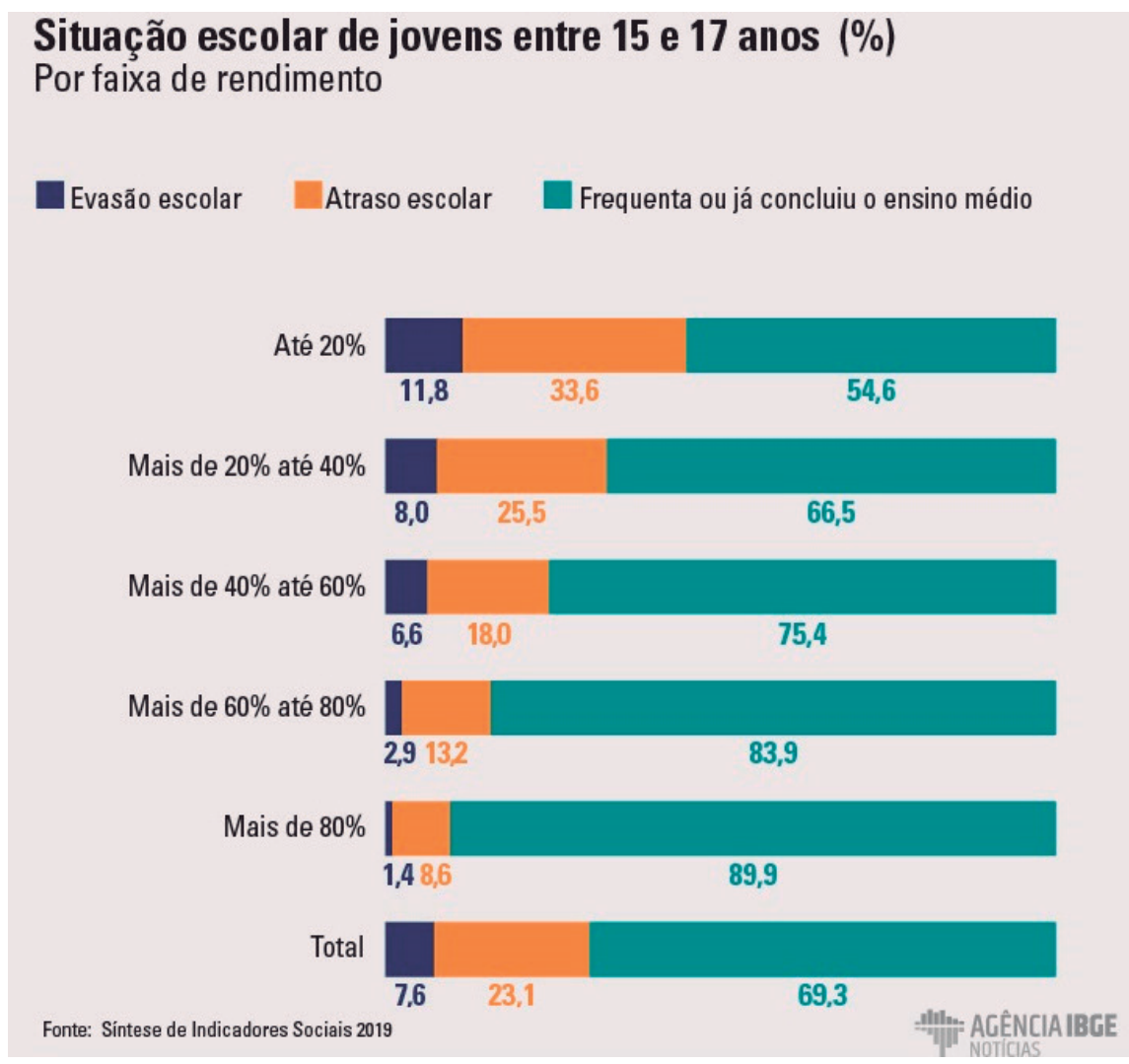

Fonte: (SARAIVA, 2019). 
Logo, levando em conta as diferenças de rendas domiciliares, aquelas de maiores vantagens financeiras possuem taxas de evasão ou atraso 35,3\% menores em relação a núcleos familiares mais pobres no Brasil. Além disso, constata-se que nestas famílias quase metade dos alunos estão atrasados em termos curriculares ou mesmo já estão evadidos, dado que esses números em domicílios de renda elevada são baixos. Observando-se o total da pesquisa, mesmo que os números tenham diminuído nas últimas décadas por diversos fatores, infere-se que pelo impasse se concentrar consideravelmente em camadas excluídas da sociedade e pouco refletir em núcleos de grande renda, tal problema tende a ser ignorado em detrimento da elite segregadora.

Portanto, reitera-se que para que seja cumprido o direito nacional de universalização da educação, é necessário que uma das raízes do problema, isto é, a desigualdade social, seja imediatamente reconhecida e realmente ponderada pelas autoridades e órgãos responsáveis. Dessa forma, havendo alguma chance de ocorrer alterações no sistema social e incrementar uma vida digna e íntegra à população de maneira geral, atendendo também de maneira competente e responsável às emergências de saúde básica e de segurança.

\section{O PAPEL DA FAMÍLIA NA EVASÃO ESCOLAR}

A família desempenha um papel muito importante no que diz respeito à permanência dos adolescentes na escola, já que ela representa uma peça fundamental no desenvolvimento dos indivíduos. Santos et al. (2000) afirmam que quanto mais recursos uma família tem, mais recursos ela dedica ao investimento educacional. Portanto, conclui-se que jovens provenientes de famílias com menos capital tendem a ter uma taxa de evasão escolar maior, já que os recursos financeiros disponíveis na família são utilizados para a satisfação das necessidades básicas. Do mesmo modo, muitas vezes esses adolescentes também precisam trabalhar para contribuir com a renda familiar, não podendo, dessa maneira, se fazer presente na escola.

Segundo Barros e Mendonça (1997), alguns estudos demonstraram que existe uma ligação entre o desempenho educacional e a escolaridade dos pais. Deve-se isso ao fato de que a escolaridade dos pais eleva a renda da família e também pois o apoio dos pais é fundamental na aprendizagem dos filhos (apud SANTOS et al., 2020). Sendo assim, torna-se evidente que as famílias de baixa renda tendem a entrar em um círculo vicioso, já que os pais não possuem escolaridade e, também, com a falta de incentivo - já que os próprios não possuem base teórica e nem abundância financeira - não conseguem ajudar o filho a permanecer no ambiente escolar, aumentando as taxas de evasão escolar desses adolescentes, que por fim acabarão nas mesmas condições socioeconômicas de seus pais.

Uma pesquisa desenvolvida por Fernanda Leite Lopez de Leon e Naércio Aquino Menezes-Filho realizou uma análise descritiva dos indicadores e determinantes da reprovação, avanço e evasão escolar no Brasil, referentes à $4^{\mathrm{a}}$ e $8^{\mathrm{a}}$ séries do ensino fundamental e $3^{\mathrm{o}}$ ano do ensino médio, no 
período 1984-1997. Os pesquisadores concluíram que estudantes com mais idade apresentam maior chance de evasão escolar condicional à reprovação quando são reprovados nos cursos, enquanto essa probabilidade é menor para aqueles que são chefes de família.

Logo, nota-se que núcleos familiares desfavorecidos, provenientes de baixa renda, por vezes acabam não sendo um fator motivador para com os estudos dos componentes mais novos. Conforme salientado por Silva Filho e Araújo (2017), "os alunos de nível socioeconômico mais baixo têm um menor índice de rendimento, portanto são mais propensos à evasão" (apud Gatti et al., 1991).

Nota-se, então, a ligação entre os fatores que tendem a desencadear o presente problema do abandono escolar, além de como as circunstâncias representam fator decisivo. Tais como o ambiente, as experiências do cotidiano e as pessoas com quem os jovens relacionam-se no contexto inserido acabam por influenciar a essa complicada e violenta realidade. De maneira a considerar o tumultuoso estágio da adolescência em que o sujeito está passando, se transformando e aprendendo a partir das práticas e vivências de acordo com a condição de cada sujeito e meio favorável ou não.

Viviane Mosé continua sua crítica ao ambiente escolar e sua forma de formar cidadãos e explicita um ponto de extrema importância quando se tratando da família e a permanência dos adolescentes no ambiente escolar:

\footnotetext{
Quando um aluno não aprende, especialmente nos primeiros anos, quem deve ser reprovado é a escola, a família, o Estado, não uma criança de 6 ou 7 anos; mas é somente ela que assume esse ônus. $\mathrm{O}$ alto índice de reprovação, essa transferência de responsabilidades, na verdade é o maior causador da evasão escolar, ou seja, do afastamento de jovens e crianças da escola. (MOSÉ, 2015).
}

Como a autora salienta, as responsabilidades pelo mau aproveitamento e rendimento escolar estão todos relacionados somente aos alunos, a família se coloca como autoridade na qual obriga a ida desses jovens para a escola, porém, se colocam à parte de seu aproveitamento desse ambiente. Quando a aprendizagem de inúmeros conteúdos e com uma rotina de estudos cansativa, com poucas horas de descanso e obrigações exacerbadas de resultados e pouco aprendizado, que é a escola, se coloca como um processo solitário e sem flexibilização dos processos individuais de cada estudante, essa rotina se torna muito mais difícil auxiliando além da evasão, problemas no processo de aprendizagem no futuro dessas pessoas se torna também mais provável.

De maneira que o abandono escolar se dá por um complexo e gradual processo de diversos elementos, afirma-se que o papel da família diante dessa situação possui significativa influência, porém não se sucede de forma isolada. Aliado também ao âmbito institucional de ensino quanto aos fatores sociais, a exclusão manifesta-se sob um ângulo hegemônico advindo da cultura de massa e alienação reproduzida pela escola. Ao analisar a constante passividade do ambiente educativo nas últimas décadas, Ceratti (2008) afirma que que essa se eximava da culpa ao traduzir o fracasso do objetivo da escola para uma aprendizagem ineficiente: 
A dúvida sobre a legitimidade do fracasso escolar voltada para a cultura social e política, segregadora e excludente; ou se a escola ingenuamente não reproduz essa mesma sociedade contribuindo para que os alunos continuem excluídos da sociedade (CERATTI, 2008, apud ARROYO, 2001).

Assim sendo, a própria escola pode colaborar com o crescimento dos níveis de desigualdade societária por meio de uma interpretação da realidade tomada de preconceitos e perspectivas arraigadas culturalmente. Nesse sentido, progredindo consideravelmente com as mazelas sociais ao automatizar e menosprezar o indivíduo devido seu contexto familiar, etnia ou opiniões dissemelhantes, de forma a instigar o abandono desse para com o direito de estudar. "São reflexos da forma como a escola recebe e exerce ação sobre as pessoas dos diferentes segmentos da sociedade" (SILVA FILHO; ARAÚJO, 2017).

Com o crescimento e avanço da escolarização da sociedade o ato de estudar e frequentar a escola foi, também, modificando sua importância. Hoje em dia, sendo um direito garantido o acesso à educação, o estudo se tornou um investimento para o futuro dos jovens.

Quando um pai diz que quer que seu filho entre em uma universidade para ser alguém na vida, o que ele está, sem querer, dizendo é que quem não estuda não é ninguém, não existe. Ousaria mesmo dizer que a exclusão do saber, do conhecimento, é a raiz de toda exclusão (MOSÉ, 2015).

A evasão escolar afeta além do conhecimento científico dos adolescentes, prejudica o convívio social e familiar desses jovens, pois ele significa uma perda de existência e futuro. A pressão que a escola carrega para a família dos estudantes colabora para que esses jovens enfrentem os anos letivos como meras obrigações institucionais, o estudo se torna algo para agradar um grupo familiar, perdendo o seu sentido originário. Com isso, não há uma aprendizagem significativa, que mude as percepções do sujeito sobre a forma que interpreta o mundo, se tornando um conhecimento raso e temporário.

Portanto, com a perda do aproveitamento de aprendizagem o interesse em frequentar o ambiente escolar se torna cada vez menor, com grandes cobranças dentro das instituições juntamente com o um período de muito descobrimento pessoal que é a adolescência, a família se torna, muitas vezes, um dos fatores nos quais colaboram para a evasão escolar. Como citado anteriormente, a família é muito importante para a permanência dos adolescentes nas escolas, logo, quando ela está fragilizada a permanência no ambiente escolar também se coloca em risco.

\section{COMO A ESCOLA INFLUENCIA NO PROCESSO DE EVASÃO ESCOLAR}

Segundo o artigo 205 da Constituição, promulgada em 1988, a educação é direito de todos e deve ser incentivada "visando ao pleno desenvolvimento da pessoa, seu preparo para o exercício da cidadania e sua qualificação para o trabalho" (BRASIL, 1988). Nesse artigo, reconhece-se a educação 
sendo um direito de todos, pois deriva-se da noção democrática do Estado de direito brasileiro, de acordo com o princípio da dignidade da pessoa humana, presente no artigo $1^{\circ}$ da Constituição Federal de 1988. Da mesma forma, compreende-se a educação como parte dos direitos sociais presentes na Constituição, presentes no título II, denominados “Dos Direitos e Garantias Fundamentais".

No entanto, apesar de ser um direito garantido por lei, não se tem a garantia de que, na prática, esse direito vai ser assegurado. Percebe-se, portanto, que a educação não tem tido pleno alcance a todos os cidadãos. Igualmente, a efetiva aprendizagem acaba se tornando um desafio ainda maior ao analisar a realidade do contexto das escolas, aumentando a taxa de evasão escolar e o não acesso universal ao ensino.

Sabe-se que uma das causas da evasão escolar se dá na própria dificuldade dessas instituições de propiciarem um espaço acolhedor e atrativo em que possibilitasse um aprendizado de qualidade e consciência para com os jovens. Este, seria de maneira a causar no estudante a vontade de buscar conhecimento por si próprio que lhe desenvolva racionalmente independente da obrigatoriedade de frequência diária num espaço físico. Assim, transformando-se e visando proporcionar bem-estar à sociedade por meio empatia de forma prática, evoluindo positivamente junto às pessoas inseridas em seu meio social ao compartilhar informações construtivas.

Nesse contexto, segundo Freire (1982), o ato de estudar necessita de persistência e atenção. “O aluno com dificuldades específicas de aprendizagem não apresenta, de início, problemas de motivação, se bem que progressivamente pode se sentir incapaz de realizar as tarefas propostas" (CERATTI, 2008). Entretanto, é notório que o contexto escolar é um dos causadores do abandono entre adolescentes devido a falhas do processo educacional.

O ambiente abordado deveria ser organizado em vários âmbitos, como higiene, organização, estrutura, atenção individualizada e, principalmente, preparo docente que respeitasse o tempo de maturação e processamento mental de cada aluno. Este, que aja apoiado além do conteúdo básico pedagógico, nos quesitos psicológicos dispondo de uma equipe multidisciplinar e instigante que estimule a curiosidade do estudante. Da mesma maneira, no que tange a ineficácia da equipe orientadora,

Educadores têm colaborado a cada dia para o problema se agravar, mediante a utilização de um método didático superado ou de uma prática cristalizada como por inexperiência, acabam por desenvolver o conteúdo de forma descontextualizada e sem sentido para o aluno (SILVA FILHO; ARAÚJO, 2017).

O fato de a profissão de educador ser atualmente bastante desvalorizada pela sociedade e órgãos governamentais que deveriam fomentar essa classe é um fator desestimulante no cenário geral do ambiente estudantil. Há profissionais que abrangem dificuldades em singularizar e reconhecer no aluno distintos perfis, capacidades, sendo propiciador de afastar o aluno por considerar-se inferior e incapaz ao não acompanhar o ritmo da turma. De acordo com os mesmos autores citados acima, "as práticas escolares devem, necessariamente, compreender as dimensões 
políticas, históricas, socioeconômicas, ideológicas e institucionais que envolvem o educando" (apud PATTO, 1999).

As práticas educativas atuais evidenciam caráter antiquado e muitas vezes pautado em um conteúdo desatualizado que já mais não condiz com o contemporâneo experienciado por quem tenta aprender. Compreendido que o receptor não processa a informação por não ter cunho elucidativo, é necessário que as escolas desenvolvam novos meios de modificar a transmissão, permitindo-se conectar com inovadoras didáticas acadêmicas. "Os desdobramentos tenderão a repercutir para a obtenção de um estudante mais motivado e, assim, mais engajado no meio" (MENDES, 2013).

Brandão e colaboradores (1983) explicam que os alunos de nível socioeconômico mais baixo têm um menor índice de rendimento escolar e, portanto, têm maior propensão a evadirem da escola. Deve-se isso em razão desses jovens necessitarem trabalhar para contribuir com a renda familiar, e, portanto, cansados dessa rotina e desmotivados a estudar pela baixa qualidade do ensino e de oportunidades, interrompem os estudos sem completar o ensino médio. Diferentemente do que acontece com os alunos de classe dominante, os quais têm tempo para os estudos e para se dedicar a outras atividades complementares e de aperfeiçoamento.

Nesse sentido, a escola torna-se responsável pelo sucesso ou fracasso dos alunos, sendo este último referente, principalmente, aos alunos pertencentes às classes menos favorecidas economicamente. De acordo com Cunha (1993), a evasão e a reprovação dos alunos são reflexos da maneira com que a escola exerce ações sobre as populações dos diferentes segmentos sociais, já que ela culpabiliza os próprios alunos pelo seu fracasso escolar. Essa ideia baseia-se na doutrina liberal, a qual defende que as pessoas são responsáveis pelo seu fracasso ou sucesso.

Visto que o adolescer é uma etapa bastante complexa da vida por ocasionar além de mudanças físicas, psicológicas, sociais e cognitivas, as demandas que surgem podem suplicar repentina responsabilidade ao passo de ter de lidar com as próprias emoções e novos questionamentos a respeito da própria identidade e de perspectivas para o futuro. Nessa perspectiva, afirma-se que:

A educação deve ter o compromisso de assumir um papel fundamental no processo de construção e transformação da sociedade e não de reposição de estigmas e enquadramento à lógica imposta pelo modo de produção capitalista, como o objetivo de formar indivíduos ativos capazes de agir de modo consciente, social, universal e livre (CARDOSO E FONSECA, 2019, p. 11).

Nesse momento, seria de suma importância que o âmbito escolar, a equipe docente e a grade curricular estivessem preparadas para compreender e auxiliar nesse turbilhão de emoções e dúvidas a respeito de si próprio e do mundo. Dessa forma, objetivando que o sistema sobretudo considerasse as diferentes condições e as realidades de cada aluno, além de fomentar perspectivas reflexivas de constante aprendizado, se responsabilizando na formação de cidadãos efetivamente inclusos na sociedade. Todavia, os reflexos do desestruturado conjunto educacional se dão primordialmente nos estigmas 
resistentes, na infraestrutura precária e na segregação social, além da banalização da educação que fomentam gradativamente as circunstâncias para a prática do fenômeno violento do abandono escolar.

Segundo a ideia dos autores acima citados, “o educador deve estabelecer uma relação consciente com seu trabalho, compreendendo seu importante papel e compromisso com a formação humana" em vista de que o processo pedagógico transforma também a própria formação identitária. Isso se dá de maneira a compreender o sentido de não promover uma construção alienante e fracassada junto ao educando. Porém, o tamanho despreparo daqueles, muitas vezes manifestado na intolerância, faz questionar se tiveram uma adolescência adequada e esclarecida, se sabem realmente lidar com pessoas e se ao menos entendem os intensos sentimentos positivos e negativos presentes na adolescência, visando a ainda não maturação completa do cérebro.

Portanto, percebe-se que é urgente a criação de um novo modelo de escola, a qual seja inclusiva e pautada no amor, no respeito e na igualdade. Diversos autores, desde o século passado, já criticavam o modelo de escola conteudista e isolada da sociedade, o qual contribui significativamente para a evasão escolar, e afirmavam a necessidade de uma mudança no padrão escolar e nos comportamentos dos professores e alunos. Lev Vygotsky, por exemplo, postulava que é necessário um educador ativo e determinado, o qual deve respeitar e entender o processo individual de cada aluno, considerando seu estágio de aprendizagem e não generalizando todos os estudantes, pois isso desmotiva aqueles que não estão no estágio de conhecimento proposto por determinada série escolar, já que não os estimula a ir além de sua capacidade. Paulo Freire, do mesmo modo, acreditava que a educação deve ser libertadora, com a escola construindo conhecimentos sobre a vida cotidiana e de autoconhecimento. Para ele, não deveria existir uma hierarquia no processo de aprendizagem, mas sim igualdade entre professores e alunos e esses entre si (MOREIRA, 1999).

\section{A PSICOLOGIA NO CONTEXTO DE EVASÃO ESCOLAR}

A evasão escolar caracteriza-se por ser um grave problema na educação brasileira. Sabe-se, por exemplo, que 12,9\% e 12,7\% dos alunos matriculados na $1^{\mathrm{a}}$ e $2^{\mathrm{a}}$ série do Ensino Médio evadiram da escola durante os anos de 2014 e 2015. Referente ao $9^{\circ}$ ano do ensino fundamental, a taxa de evasão foi de 7,7\%, enquanto a $3^{\text {a }}$ série do Ensino Médio totalizou 6,8\% de alunos evadidos. Nesse sentido, a psicologia apresenta-se como uma peça fundamental na luta contra a evasão escolar, já que ela é a principal responsável por avaliar os problemas de desenvolvimento e aprendizagem dos alunos, os quais podem ser um fator preditor da evasão escolar.

O papel da psicologia nessa situação se dá no fato de que o abandono escolar é resultado gradual de condições exteriores e interiores; ou seja, é causado por influências de contexto social e cultural, como também de fatores que dizem respeito à subjetividade e saúde socioemocional do sujeito. Logo, é notória a relação pois, tendo a ciência psicológica como estudo do ser humano e seus 
fenômenos psicológicos, é intrínseca a tamanha utilidade e necessidade. "Ele deve ajudar as pessoas a superarem sua identidade alienada, pessoal e social, ao transformar as condições opressivas do seu contexto" (MARTIN-BARÓ, 1997).

O psicólogo pode interferir nos fatores de proteção que podem ser desenvolvidos, voltando-se para os aspectos resilientes, que não perdem a estrutura em situação de estresse, olhando-se para o sucesso e não para o fracasso escolar. Os fatores orgânicos (distúrbios, dificuldades ou características individuais) e os fatores de estresse ( que incluem as experiências vividas em sua rede social e consequências da exposição aos conflitos ambientais) atingem, inevitavelmente, as pessoas até antes do nascimento, mas na fase pré-escolar ou escolar, quando o desenvolvimento biopsicossocial permite que a criança se insira na comunidade que a rodeia, o seu ajustamento social e saúde mental estarão tomando forma, determinando seu futuro. O exposto não afetado (resiliente) tem fatores de proteção, que precisam ser analisados para que se possa fazer a prevenção de risco. (VALLE, 2013).

A adolescência é um período no qual o cérebro está em constantes transformações, suas capacidades cognitivas estão também em alta, facilitando a aprendizagem, porém, por ser um momento de maturação cerebral há também aspectos nos quais devem ser constantemente observados para uma melhor aprendizagem e convívio desses alunos. Pessoas com problemas no seu desenvolvimento, como também com doenças psíquicas desde seu nascimento precisam de uma maior atenção dos psicólogos, ou seja, no ambiente escolar esta diversidade é muito grande, colocando os professores em sobrecarga quando exigimos que consigam suprir a necessidade de todos, outro fator no qual a importância de psicólogos nesse contexto é grande.

Quando não há a oportunidade de um aluno com dificuldades cognitivas ser incluso no contexto escolar, não possuindo apoio da equipe desse contexto e também familiar, esses alunos acabam gradativamente se afastado do ambiente escolar e se tornando cada vez mais propensa a sua saída.

Para que o constante e alarmante problema do abandono escolar seja efetivamente contido e encaminhado a uma significativa redução, além da reflexão da estrutura coordenadora da escola junto a políticas públicas, muito a ser feito em vista da abordagem de múltiplas áreas ademais. "É uma questão preocupante que impõe a necessidade de reflexão por parte de todos os profissionais envolvidos no processo educacional a exemplo do profissional da psicologia" (SOUZA et al, 2017). Os domínios acadêmicos emergidos no século XIX e, principalmente, no século XXI, referem-se a experimentações e elaborações bibliográficas que de alguma forma colaborasse com a dinâmica das mais variadas áreas que englobam o indivíduo como ser individual, coletivo, diverso e modificador das relações e do meio ambiente.

Portanto, campos das ciências humanas, sociais e biológicas afloram-se de maneira a apresentar soluções a dilemas que limitem o sujeito. Este é o caso de cursos como a Sociologia, Antropologia, Filosofia, e, sobretudo, a Psicologia, que se tornaram significativamente relevantes com a consolidação de momentos históricos marcantes. Esses, indicadores de um início do acelerado processo de transformações, como as Revoluções Industriais e cenários caóticos do pós-guerra. 
Dado isso, é de extrema relevância a intervenção de equipes multidisciplinares que orientem anseios, impasses, instituições e pessoas de distintas funções sociais. Essas, de maneira a possibilitar uma adequada qualidade de vida, aprendizagem e trajetória conjunta na civilização que lide com as mazelas, individuais, internas, externas e sociais. Nesse sentido, discorre-se acerca dos reflexos evidenciados no que se refere ao assunto, bem como das consequências e importância da visibilidade desse problema:

O problema da evasão escolar no Brasil é um dos grandes desafios que a educação do país enfrenta, principalmente o ensino público, pois está relacionado de forma direta ou indireta a fatores de ordem social, cultural, político, econômico e educacional. (SOUZA et al, 2017).

Portanto, o serviço da atuação psicológica por meio dos profissionais no cenário comunitário, sobretudo visando o que abrange o estágio da adolescência, junto a Psicologia Educacional, tem relevante papel integrativo e resolutivo. Por meio disso, promove-se uma melhor dinâmica da constituição psíquica e nos contextos do meio inseridos em cada realidade. Dessa forma, contribuindo para o papel introspectivo da tomada de decisões e auxiliando na motivação e no autoconhecimento.

Como citado anteriormente, um dos fatores sociais no qual estimula a evasão escolar é o rótulo que a sociedade coloca em muitos adolescentes, como por exemplo "delinquente", essa pressão social em um momento de descobrimento que é a adolescência é sem dúvida muito desafiadora. O papel do psicólogo nesse contexto é possuir o olhar cuidadoso e atento para além do que a escola comunica, é necessário analisar o contexto social no qual interfere cada aluno.

$\mathrm{O}$ ambiente escolar ensina a seus alunos muito mais do que somente as disciplinas ministradas, o convívio com colegas, estrutura física da escola, funcionários (as) também interferem na saúde mental e aprendizado desses adolescentes. Ou seja, é necessário que vários fatores dentro desse contexto funcionem adequadamente para que todos desse convívio estejam aptos para ensinar e aprender, o psicólogo inserido na instituição é além de um dos fatores dentro desse contexto, e sim alguém que deve interferir para a sua melhora.

Além disso, o psicólogo possui a função de criar pontes de diálogo entre alunos e professores, construindo uma comunicação mais fácil para todos, uma vez que os escuta e é atento a seus comportamentos. Os ambientes escolares, principalmente em turmas de ensino médio, possuem pessoas em constante transformação e descobrimento sobre o mundo, colocando-as em situações de reflexões sobre o futuro e sobre si mesmas; o psicólogo está presente nesse espaço para auxiliar nesse momento de intensa subjetivação, e como consequência, melhorar o convívio entre todos.

Tendo em vista os fatores nos quais interferem na saúde mental dos adolescentes dentro das escolas se torna possível entender também onde a psicologia faz seu trabalho. "Quando a educação não é libertadora, o sonho do oprimido é ser o opressor" (FREIRE, 1938), no contexto da evasão escolar entre adolescentes é de extrema importância mostrar a educação como mais uma forma de 
liberdade, além disso, tornar esses jovens livres de suas próprias correntes de problemas psíquicos para que permanecer na escola não seja uma obrigação, e sim um ato livre.

\section{CONSIDERAÇÕES FINAIS}

Portanto, torna-se evidente que o fenômeno da evasão escolar representa um grave e recorrente problema na sociedade ao ameaçar o andamento da democracia por ter origem e afetar diretamente o âmbito da educação em relação aos que se encontram na conflituosa e intensa fase da adolescência. A importância da educação se dá por simbolizar uma virtude básica e necessária no funcionamento de uma sociedade igualitária que instigue o senso crítico, o direito de escolha e liberdade, além de propiciar uma boa qualidade de vida. Ademais, transformando a própria realidade ao auxiliar na construção e mudança das condições dos outros indivíduos para que contribua para com o respeito e o entendimento dos outros, indo de encontro ao sistema capitalista alienante que visa a produção em massa e subverte a individualidade.

As causas do abandono escolar expressam-se por variados fatores e geralmente ocorrem pela somatória de aspectos sociais, econômicos, familiares e educacionais, visto que o abandono representa uma das fraquezas desse sistema. Já as consequências, também. O fracasso estudantil colabora com a segregação social, visto que a escola não cumpre com o dever e a responsabilidade primária de promover o desenvolvimento do indivíduo como cidadão ao socializar o conhecimento e proporcionar a visão crítica e moral para que lide adequadamente com pessoas e desafios do futuro. O sistema escolar representa uma barreira no combate à evasão, visto que o ambiente muitas vezes não é acolhedor, os professores são desmotivadores e os métodos de aprendizagem, falhos e retrógrados.

Em se tratando da família, esta é decisiva nessa condição, já que ela é uma peça fundamental no desenvolvimento dos indivíduos. Outrossim, compreende-se, hoje, que a escolaridade dos pais é um fator crucial na permanência dos jovens na escola, pois a escolaridade dos pais eleva a renda da família e, quanto maior a renda familiar, mais recursos para investir na educação esse núcleo familiar possui. Portanto, indivíduos de baixa renda tendem a entrar num círculo vicioso, visto que necessitam deixar a escola para contribuir com a renda familiar e, dessa forma, terão menos condições de contribuir na educação de seus futuros filhos.

Nesse sentido, as ciências psicológica e sociológica representam papel fundamental para uma significativa redução do impasse. A Psicologia Educacional é capaz de promover um entendimento dos alunos e dos pais desses alunos sobre a importância da permanência na escola e, também, de que maneira os estudos impactam na vida futura dos indivíduos. Igualmente, os psicólogos têm potencial para auxiliar a escola na criação de práticas mais inclusivas e respeitosas.

Assim sendo, sugere-se que se façam mais pesquisas sobre a temática para que seja de fato viabilizada e mobilize a sociedade, por meio de pesquisas e diminuição das desigualdades sociais. 
Isso, com o objetivo de alterar a realidade das práticas educacionais e a maneira dos estudantes de se relacionarem com os professores, com a escola e consigo mesmos para a construção de um ambiente atrativo e uma perspectiva de vida motivada e promissora.

\section{REFERÊNCIAS}

BARDIN, Laurence. Análise de conteúdo. Lisboa: Edições 70, 1977.

BARROS, Ricardo Paes de; MENDONÇA, Rosane. O impacto do crescimento econômico e de reduções no grau de desigualdade sobre a pobreza. Texto para discussão $\mathrm{n}^{\mathrm{o}} 528$. Rio de Janeiro: IPEA, 1997. Disponível em: https://bit.ly/3jc013t. Acesso em: 14 dez. 2020.

BRANDÃO, Zaia. et al. O estado da arte da pesquisa sobre evasão e repetência no ensino de $1^{\circ}$ grau no Brasil. In Revista Brasileira de Estudos Pedagógicos, v. 64, nº 147, maio/agosto 1983, p. 38-69.

BRASIL. Constituição Federal de 1988. Disponível em: https://bit.ly/3n4OmV9. Acesso em: 20 out. 2020 .

CARDOSO, Priscila Carla; FONSECA, Débora Cristina. ADOLESCENTES AUTORES DE ATOS INFRACIONAIS: DIFICULDADES DE ACESSO E PERMANÊNCIA NA ESCOLA. Psicol. Soc., Belo Horizonte, v. 31, e190283, 2019. Disponível em: https://bit.ly/3aSxVFy. Acesso em: 21 out. 2020.

CERATTI, Márcia Rodrigues Neves. Evasão escolar: causas e consequências. Dia a Dia Educação, Curitiba, dezembro, 2008. Disponível em: https://bit.ly/3jft3z1. Acesso em: 20 out. 2020.

CUNHA, Maria Isabel da. O bom professor e sua prática. 6 ed. São Paulo: Papirus, 1996.

FREIRE, Paulo. Ação cultural para a liberdade e outros escritos. 8. ed. Rio de Janeiro: Paz e Terra, 1982.

GALlO, Alex Eduardo; WILLIAMS, Lúcia Cavalcanti de Albuquerque. A escola como fator de proteção à conduta infracional de adolescentes. Cad. Pesqui. São Paulo, v. 38, n. 133, p. 41-59, abr. 2008. Disponível em: https://bit.ly/3ARRDfi. Acesso em: 21 out. 2020.

GIL, Antonio Carlos. Como elaborar projetos de pesquisa. 4. Ed. São Paulo: Atlas, 2002. 
IBGE - Instituto Brasileiro de Geografia e Estatística. Pesquisa Nacional por Amostra de Domicílios Contínua, 2018.

LINCOLN, Yvonna S.; DENZIN, Norman K. O planejamento da pesquisa qualitativa: teorias e abordagens. 2. edição. Porto Alegre: Artmed, 2006.

LOPEZ DE LEON, Fernanda L.; MENEZES-FILHO, Naércio Aquino. Reprovação, avanço e evasão escolar no Brasil. Pesquisa e Planejamento Econômico, Rio de Janeiro, v. 32, n. 3, p. 417-451, dez. de 2002. Disponível em: https://bit.ly/2Z3dlAd. Acesso em: 20 out. 2020.

MARTIN-BARO, Ignácio. O papel do Psicólogo. Estud. psicol. (Natal), Natal, v. 2, n. 1, p. 7-27, jun. de 1997. Disponível em: https://bit.ly/3FXXcfR. Acesso em: 20 out. 2020.

MEC. Instituto Nacional de Estudos e Pesquisas Educacionais (Inep). Inep divulga dados inéditos sobre fluxo escolar na educação básica. [Online]. Brasília: Inep, 2017. Disponível em: https://bit.ly/ 3DPEMfr. Acesso em: 22 out. 2020.

MENDES, Marcelo Simões. Da inclusão à evasão escolar: o papel da motivação no ensino médio. Estud. psicol. (Campinas), Campinas, v. 30, n. 2, p. 261-265, jun, 2013. Disponível em: https://bit.ly/ 3aLkYxB. Acesso em: 20 out. 2020.

MINAYO, Maria Cecília de Souza. Pesquisa social: Teoria, Método e Criatividade. $21^{\mathrm{a}}$ edição. Petrópolis, RJ.: Vozes Ltda., 2002.

MOREIRA, Jacqueline de Oliveira et al. A escola e a semiliberdade: a importância do diálogo. Psicol. rev. (Belo Horizonte), Belo Horizonte, v. 21, n. 1, p. 50-65, jan. 2015. Disponível em: https://bit.ly /2YY1jrZ. Acesso em: 21 out. 2020.

MOREIRA, Marco Antônio. Teoria de aprendizagem. São Paulo: E.D.U., 1999.

MOSÉ, V. Introdução: A escola e os desafios contemporâneos. Em: . A escola e os desafios contemporâneos. 4. ed. Rio de Janeiro: Civilização Brasileira, 2015.

SANTOS, D., BARROS, R. P. de, MENDONÇA, R., QUINTAES, G. Determinantes do desempenho educacional do Brasil. Texto apresentado no Encontro da Anpec, 2000. 
SARAIVA, Adriana. IBGE - Instituto Brasileiro de Geografia e Estatística. Estatísticas Sociais, Agência de Notícias IBGE. Abandono escolar é oito vezes maior entre jovens de famílias mais pobres, 2019. Disponível em: https://bit.ly/3n4n5SH. Acesso em: 16 dez. 2020.

SILVA FILHO, R. B; ARAÚJO, R. M. DE L. Evasão e abandono escolar na educação básica no Brasil: fatores, causas e possíveis consequências. Educação Por Escrito, Porto Alegre, v. 8, n. 1, p. 35-48, 29 jun. 2017. Disponível em: https://bit.ly/3AMZ5bv. Acesso em: 20 out. 2020.

SOUZA, Josinaldo Furtado De et al. "Evasão escolar e psicologia educacional: reflexões sobre a realidade brasileira". Anais IV CONEDU. Campina Grande: Realize Editora, 2017. Disponível em: https://bit.ly/3pdfCUf. Acesso em: 22 out. 2020.

VALLE, Luiza Elena Leite Ribeiro. Psicologia escolar: um duplo desafio. Psicol. cienc. prof. v. 23, n. 1 Brasília Mar. 2003.

FORMIGA, Nilton S.; SÁ, G. L.; BARROS, S. M. As causas da evasão escolar? Um estudo descrito por jovens brasileiros. Psicologia. PT. A, v. 617, 2011. Disponível em: http://www.psicologia. pt/artigos/textos. Acesso em: 13 dez. 2020. 